\title{
La razón del sentimiento. Modernidad, emociones e historia contemporánea
}

\author{
Birgit AschmanN \\ Universidad Humboldt de Berlín \\ birgit.aschmann@hu-berlin.de
}

Recibido: $15 / 06 / 2014$

Aceptado: 02/07/2014

\section{RESUMEN}

En los siglos XIX y XX se impuso la opinión de que la política solo se hacía con la cabeza y no con ninguna otra parte del cuerpo o con el alma. Las emociones, pues, quedaron subestimadas por mucho tiempo hasta que Georg Simmel, quien fuera redescubierto a finales del siglo XX como el precursor de la sociología de las emociones, llamó la atención sobre cómo los vínculos emocionales entre los hombres son los que los unen y los desunen, en cualquier circunstancia y en cualquier etapa histórica. Tras el giro emocional generado por los acontecimientos del 11 de septiembre del 2001, considerados el catalizador del cambio de tendencia historiográfica, lo emocional está presente en la agenda historiográfica y se han puesto en duda los conceptos de Modernidad que implícitamente se basaban en un retroceso paulatino de la emocionalidad a favor de una racionalidad en expansión. Para examinar todo esto más a fondo, el artículo analiza el papel de las emociones en las metanarrativas de la Modernidad; los diversos aspectos que o bien ponen en duda esta perspectiva, o bien la hacen parecer sumamente problemática, y pone en práctica estos postulados tomando como ejemplo manifestaciones concretas del miedo. Se responderá finalmente a la pregunta de qué consecuencias puede tener el estudio de las emociones para un nuevo concepto de Modernidad.

Palabras clave: Emocionalidad, racionalidad, modernidad, giro emocional.

\section{The feelings' reasons: Modernity, emotions and contemporary history}

\begin{abstract}
In the19th and 20th centuries, prevailed the view that the policy is only made with the head and not with any other part of the body or the soul. Emotions, then, were underestimated for a long time. But in 1908, Georg Simmel, who was rediscovered in the late 20th century as "the precursor of the sociology of emotions, drew attention to how the emotional bonds between men unite (and separate) them under any circumstances and in any historical period. After the emotional turn generated by the events of September 11, 2001, considered the catalyst for change historiographical trend, the emotional is present in the historiographical agenda and has called into question the concepts of modernity implicitly relied on a gradual decline of emotions in favor of rationality. To examine this deeper, the article analyzes the role of emotions in the metanarratives of modernity and implements these principles using the example
\end{abstract}


of concrete manifestations of fear. It will finally answer the question of what consequences it can have the study of emotions to a new concept of modernity.

Key words: Emotional, rationality, modernity, emotional turn.

\section{Introducción}

"La política se hace con la cabeza, no con otras partes del cuerpo o del alma". ${ }^{1}$ Esta frase de Max Weber refleja la opinión que dominaba en los siglos XIX y XX con respecto a la relevancia de la racionalidad, en la que "la cabeza" era considerada como sinónimo de razón, y que desde la Ilustración disfrutaba de un aprecio especial por parte de las sociedades "modernas". Esto contribuyó a que la importancia de las emociones fuera subestimada por mucho tiempo. Georg Simmel, quien fuera redescubierto a finales del siglo XX como "el precursor de la sociología de las emociones", ${ }^{2}$ había descrito ya en 1908 los vínculos emocionales entre los hombres como "la maravillosa capacidad de enlazamiento de la sociedad":

Que los hombres se miren unos a otros, y que estén celosos unos de otros, que se escriban cartas o que almuercen juntos; que ellos, mucho más allá de cualquier interés visible, se toquen de manera simpática o antipática [...] todas esas miles de relaciones, de persona a persona, celebradas, momentáneas o duraderas, conscientes o inconscientes $[\ldots]$ nos unen continuamente. $^{3}$

La importancia central de estos vínculos se fue haciendo más visible desde el emotional turn. Precisamente fueron los acontecimientos del 11 de septiembre del 2001, que son considerados como el catalizador del cambio de tendencia historiográfica, los que pusieron claramente en evidencia que no solo los mecanismos constructivos son de transcendental importancia para la política, sino que también lo son en particular las emociones destructivas. El papel de la emocionalidad en el presente se hizo imposible de negar, lo que puso en duda todos los conceptos de Modernidad que implícitamente se basaban en un retroceso paulatino de la emocionalidad a favor de una racionalidad en expansió; or ello las emociones son un problema de central importancia para los diversos conceptos de Modernidad. Para Barbara Rosenwein, el estudio de las emociones es incluso "una buena oportunidad para poner verdaderamente a prueba el concepto de Modernidad". ${ }^{4}$ Con el ánimo de examinar esto más a fondo, a continuación me referiré, primero, al papel de las emociones en las metanarrativas de la Modernidad; segundo, resaltaré diversos aspectos

\footnotetext{
1 WEBER, Max: Politik als Beruf (Max Weber Gesamtausgabe Bd. 17), Tübingen, 1992, p. 228.

2 Cf. NEDELMANN, Birgitta: "Psychologismus" oder Soziologie der Emotionen? Max Webers Kritik an der Soziologie Georg Simmel", en Otthein RAMMSTEDT (ed.): Simmel und die frühe Soziologie. Nähe und Distanz zu Durkheim, Tönnies und Max Weber, Frankfurt a. M., 1988, pp. 11-35, p. 11.

3 SIMMEL, Georg: Soziologie. Untersuchungen über die Formen der Vergesellschaftung (1908), (Gesamtausgabe Bd. 11), Frankfurt a. M. 2001, p. 33.

4 Barbara Rosenwein en entrevista con Jan Plamper, cf. PLAMPER, Jan: "Wie schreibt man die Geschichte der Gefühle? William Reddy, Barbara Rosenwein und Peter Stearns im Gespräch mit Jan Plamper“, WerkstattGeschichte, 54 (2010), pp. 36-69, p. 64.
} 
que o bien ponen en duda esta perspectiva o bien la hacen parecer sumamente problemática; tercero, me ocuparé de la problemática del dominio social de las emociones; y cuarto, elucidaré estos postulados generales tomando como ejemplo manifestaciones concretas del miedo. Al final, será posible responder a la pregunta de qué consecuencias puede tener el estudio de las emociones para un nuevo concepto de Modernidad.

\section{Emociones en las metanarrativas de la Modernidad}

En la historiografía se impuso la concepción de ese tipo de desarrollo procesual que se contempló bajo el término de "teorías de modernización". Todos los fenómenos diversos que bajo el nombre de "procesos básicos" originaron grandes cambios en la Modernidad, como la burocratización, industrialización, secularización, etc., son aspectos que forman parte de un principio de movimiento fundamental, al que la Modernidad le ha puesto su propia huella: la caracterización del racionalismo. "El racionalismo", en palabras de Christof Dipper "es considerado como el logro más importante de la Modernidad; el mundo debe estructurarse siguiendo su receta". ${ }^{5}$ Aparte de las dificultades surgidas al querer fijar en el tiempo esta "Modernidad", el significado del concepto general "racionalismo" genera ciertos problemas. El contenido del término no surge en última instancia de la delimitación con su término opuesto: el irracionalismo. Según el diccionario DUDEN, por "irracionalismo" se entiende "la primacía de las emociones sobre la cognición del intelecto". ${ }^{6}$ En las enciclopedias del siglo XIX, el término se conocía principalmente como "contrario a la razón"” o como "falta de razón". ${ }^{8}$ En consecuencia, se debe entender la imposición del racionalismo como un proceso en el que las emociones fueron siendo reprimidas cada vez más. En esta idea subyace la imagen de una balanza: un mayor peso de la emoción significa menos peso de la racionalidad y al revés. El gran relato históricoemocional de la era del "racionalismo" conduce inevitablemente a la suposición de que se da una reducción significativa, compleja y, a fin de cuentas, lineal de los afectos, sentimientos y pasiones a favor de la eficiencia de la razón. Precisamente son estos los modelos con los cuales los sociólogos Max Weber y Norbert Elias describieron los grandes procesos sociales y mentales de la Edad Moderna. "Los impulsos, las emociones, según Elias, se manifestaron antes de la Edad Moderna “de manera más libre, más directa, más desvelada de lo que lo fue después". ${ }^{9}$ De esta manera, Elias presupone un cambio en "las

\footnotetext{
5 DIPPER, Christof: "Moderne, Version 1.0“ en Docupedia-Zeitgeschichte, 25.8.2010, URL: http:// docupedia.de/zg/Moderne, p. 1.

6 Duden Online, http://www.duden.de/suchen/dudenonline/Irrationalismus (02.01.2014).

7 PIERER, H.A. (ed.): Universal-Lexikon der Gegenwart und Vergangenheit oder neuestes encyclopädisches Wörterbuch der Wissenschaften, Künste und Gewerbe, 2. Auflage, Bd. 15, Altenburg 1843, p. 275; Pierers Konversations-Lexikon, ed. por Joseph Kürschner, 7. Auflage 1890, Bd. 7, p. 1196; MEYER, Hermann J. (ed.): Neues Konversations-Lexikon, ein Wörterbuch des allgemeinen Wissens, 2. Auflage, Bd. 9, Hildburghausen, 1865, p. 430.

8 Meyers Konversations-Lexikon. Ein Nachschlagewerk des allgemeinen Wissens, 5. Auflage, Bd. 9, Leipzig/ Wien 1897, p. 343. Herders Conversations-Lexikon. Kurze aber deutliche Erklärung des Wissenswerthesten aus dem Gebiete der Religion, Philosophie, Geschichte, Geographie, Sprache, Literatur, Kunst, Natur- und Gewerbekunde, des Handels, der Fremdwörter, 2. Auflage, Bd. 3, Freiburg i. Br., 1878, p. 111.

9 ELIAS, Norbert: Über den Prozeß der Zivilisation: Soziogenetische und psychogenetische Untersuchungen, Bd. 1: Wandlungen des Verhaltens in den weltlichen Oberschichten des Abendlandes
} 
estructuras afectivas y de control del ser humano" que a lo largo de una gran cadena generacional se condujo en la misma dirección, a saber [...], en dirección a una intensificación y a una diferenciación del control cada vez mayor". ${ }^{10}$

Desde una perspectiva historiográfica, esta narrativa se enunció con un impacto duradero en la obra de Johann Huizinga de 1919 "El otoño de la Edad Media", según la cual el mundo del siglo XV estaba profundamente marcado por una gran emocionalidad, del mismo tipo que marca el mundo de la experiencia de los niños de hoy. "El hombre moderno" según Huizinga, "no tiene idea de la extravagancia desenfrenada y de la inflamabilidad del ánimo medieval". ${ }^{12}$ Gracias a esta emotividad desenfrenada, la Edad Media fue concebida - critica la medievalista Barbara Rosenwein - como "la niñez de la humanidad", ${ }^{13}$ de la que se diferenciaba fundamentalmente la política dominada por la burocracia y el protocolo en "la edad adulta". ${ }^{14}$ Ya no son las emociones desinhibidas, sino el sobrio cálculo según criterios de utilidad el que predomina en la "Modernidad". 15

\section{Argumentos en contra de la narrativa del control progresivo de los afectos en la "Modernidad"}

Los argumentos en contra del postulado del control progresivo de los afectos en la "Modernidad" se pueden resumir en tres aspectos: primero, las dimensiones temporales se han vuelto discutibles, en particular la fijación de un posible término así como el supuesto comienzo de un desarrollo teleológico aceptado. El "desencantamiento del mundo" (Max Weber) y el "creciente control de los afectos" (Norbert Elias) desembocan en la tesis de una idea teleológica del (por decirlo de una manera provocadora) fin inminente de la emocionalidad incontrolada. ¡Pero ocurrió de manera muy distinta! El fin de la emocionalidad es hoy más que nunca inimaginable. El 11 de septiembre del 2001 es considerado como el momento decisivo en el estudio historiográfico de las emociones. "Si debe haber", en palabras de Jan Plamper "un lugar de nacimiento de la historia actual de las emociones, ese lugar es Manhattan en la mañana del 11 de septiembre del 2001". ${ }^{16}$ Las emociones parecen experimentar un nuevo auge, los seres humanos actúan en términos de emociones, los políticos las manifiestan y los periodistas escriben sobre ellas. En palabras de Plamper, un "tsunami de comunicación altamente emocional" 17 aceleró el emotional turn en la historiografía, el cual era parte de aquel proceso de transformación que la actualidad parece hacer ver como "Posmodernidad". Pero no solo el fin, sino también el presunto comienzo

[Gesammelte Schriften Bd. 3,1], Frankfurt a. M., 1997, p. 370.

10 Ibid., p. 11.

11 HUIZINGA, Johann: Herbst des Mittelalters: Studien über Lebens- und Geistesformen des 14. und 15.

Jahrhunderts in Frankreich und den Niederlanden, ed. por Kurt Köster, Stuttgart 1975, pp. 1, 20.

12 Ibid., p. 18.

13 ROSENWEIN, Barbara: Emotional Communities in the Early Middle Ages, Ithaca/NY, 2006, p. 5.

14 HUIZINGA, Johann: Herbst, p. 14.

15 Cf. ROSENWEIN, Barbara: Emotional Communities, p. 5.

16 Cf. PLAMPER, Jan: Geschichte und Gefühl. Grundlagen der Emotionsgeschichte, München, 2012, p. 75; HITZER, Bettina: "Emotionsgeschichte - ein Anfang mit Folgen“, en HSoz-u-Kult 23.11.2011, http:// hsozkult.geschichte.hu-berlin.de/forum/2011-11-001 [último acceso 2.1.2014], p. 3.

17 PLAMPER, Jan: Geschichte und Gefühl, p. 73. 
de la Modernidad se ha puesto en duda bajo los augurios histórico-emocionales. Por lo general, la transición de la Edad Media a la Edad Moderna se contemplaba también, o mejor, precisamente a causa del paradigma racional, como una cesura. Los primeros estudios importantes toman como punto de partida el umbral de esta época: "El otoño de la Edad Media" de Johann Huizinga, "El proceso de la civilización" de Norbert Elias o el estudio de Jean Delumeau sobre "El miedo en Occidente". ${ }^{18}$

Sin embargo, fueron especialmente los medievalistas quienes se opusieron a la tesis de una época moderna dirigida cada vez más por los afectos. ${ }^{19}$ Por ejemplo, Barbara Rosenwein y Gerd Althoff rechazan la tesis de que la Edad Media estuviera dominada por emociones desenfrenadas. ${ }^{20}$ Todo lo contrario. Althoff resalta el papel del cálculo deliberado que subyacía en la manifestación de las emociones. ${ }^{21}$ Los rituales con fuertes erupciones de emoción son, en su opinión, parte de una comunicación simbólica sumamente reglamentada. Las localizaciones temporales del modelo de las teorías de la modernización, que suponen el comienzo de los procesos básicos alrededor del siglo XVI (¡y no antes!) para luego implicar un proceso teleológico, han sido objeto de críticas.

Segundo, cabe pensar que la tesis del control de las emociones, o mejor, de la minimización de las emociones a favor de la razón, puede partir de dos presupuestos completamente falsos, a saber: 1. El presupuesto de que las emociones son algo "completamente distinto" a la razón y por eso pueden ser separadas limpiamente de los procesos racionales. 2. La convicción de que justamente esa separación es buena y deseable para poder tomar decisiones "correctas", es decir, "sensatas". Precisamente es aquí donde vale la pena dirigir la atención a los resultados de las ciencias cognitivas en las últimas décadas, las cuales no dejan duda: cognición y emoción, razón y sentimiento no pueden ser separadas neurobiológicamente. Las conexiones de las áreas cerebrales que son las responsables de ambos sistemas, han confirmado la sospecha de que tanto la deliberación racional como el sentir emocional son indispensables para el proceso de toma de decisiones, e incluso a diversos niveles de conciencia: tanto en altos procesos cognitivos y en emociones más complejas como en procesos emocionales instintivos, los cuales, según Darwin, cumplían en un comienzo una función que prometía ventajas evolucionistas. ${ }^{22}$

18 DELUMEAU, Jean: Angst im Abendland. Die Geschichte kollektiver Ängste im Europa des 14. bis 18. Jahrhunderts, 2 Bde, Reinbek bei Hamburg, 1985. De manera similar, ver KARAN-NUNN, Susan: The Reformation of Feeling: Shaping the Religious Emotions in Early Modern Germany, New York, 2010.

19 Cf. entre otros SCHWERHOFF, Gerd: "Zivilisationsprozeß und Geschichtswissenschaft: Norbert Elias' Forschungsparadigma in historischer Sicht", Historische Zeitschrift, 266 (1998), pp. 561-605.

20 ROSENWEIN, Barbara: "Worrying about Emotions in History", The American Historical Review, 107 (2002), pp. 821-845; ROSENWEIN, Barbara: Emotional Communities, p. 5 y siguientes.

21 Cf. entre otros ALTHOFF, Gerd: "Tränen und Freude. Was interessiert Mittelalter-Historiker an Emotionen?", Frühmittelalterliche Studien, 40 (2006), pp. 1-11; idem: "Vom Lächeln zum Verlachen. Formen und Funktionen emotionaler Zeichen in mittelalterlichen Gruppen und Gemeinschaften", en: Werner RÖCKE (ed.): Lachgemeinschaften. Kulturelle Inszenierungen, Berlin, 2005, pp. 1-14; idem.: "Empörung, Zerknirschung. "Emotionen" in der öffentlichen Kommunikation des Mittelalters", Frühmittelalterliche Studien, 30 (1996), pp. 60-79. Las tesis del uso calculado de las emociones como medio de comunicación en la Edad Media fueron puestas en duda por el historiador de las mentalidades vienés Dinzelbacher, cf. DINZELBACHER, Peter: Warum weint der König? Eine Kritik des mediävistischen Panritualismus, Badenweiler, 2009.

22 Cf. DARWIN, Charles: Der Ausdruck von Gemüthsbewegungen bei dem Menschen und den Thieren, 3. Auflage Stuttgart, 1877. 
Es por eso que los científicos propusieron fusionar los conceptos cognición y emoción en "cogmoción". ${ }^{23}$ Antonio Damasio, principalmente con su informe sobre Phineas Gage, ha popularizado la tesis de que los centros cognitivos de la emoción juegan un papel muy importante en el proceso de toma de decisiones. Gage era un obrero norteamericano, quien en un accidente se perforó la cabeza con una vara de hierro, aparentemente sin consecuencias, hasta que se comprobó que a causa de un daño en las áreas cerebrales de la emoción, éste ya no era capaz de tomar decisiones "sensatas". ${ }^{24}$

El auge actual de la investigación cognitiva llevó finalmente a la derrota de la tesis de que a) es posible y b) es deseable desencantar emocionalmente a la Modernidad. Las emociones son imprescindibles, y sobre todo lo son para poder actuar racionalmente. Después de todo, estas interrelaciones no son nada nuevo, simplemente habían sido olvidadas. El mismo Descartes, a cuyo dualismo se le atribuye la separación entre emoción y razón, le había concedido a las emociones un gran significado. ${ }^{25}$ La época de la ilustración no fue en absoluto una fase de represión de las emociones, sino por el contrario, uno de los grandes momentos de valoración de los sentimientos. ${ }^{26}$ Solo hasta comienzos del siglo XIX - y luego de manera continua con consecuencias hasta entrado el siglo XX - pudo imponerse el dualismo cartesiano, como reacción a los excesos emocionales de la Revolución Francesa. La causa de esta imposición, según William Reddy, el historiador de emociones norteamericano más conocido, fue la experiencia del fracaso de un "régimen emocional" que quería llevar a la libertad pero que terminó en terror. ${ }^{27}$ En lugar de la vieja apología de las pasiones surgió entonces, a partir de 1794, el profundo escepticismo frente a la capacidad política de las emociones, las cuales fueron expulsadas de la esfera de lo público y relegadas al ámbito femenino del hogar. Este enfoque destaca la relevancia del cambio de época alrededor de 1800, que también se manifestó en el plano de las emociones, lo que no sorprende en el sentido de que cada régimen político, siguiendo de nuevo a Reddy, tiene su propio régimen emocional. Precisamente es esta constatación la que pone en duda los conceptos prevalecientes y sugiere la idea de que a lo largo del tiempo en contextos diversos ha habido un cambio en el sistema normativo socio-emocional, y que finalmente también se ha dado un cambio en las experiencias emocionales. ${ }^{28}$

Es este el tercer aspecto que debe ser mencionado en contra de la metanarrativa de un control progresivo de los afectos en la Modernidad. Entre los siglos XVI y XX siempre

23 BARNETT, Douglas / HORN RATNER, Hilary: "Introduction: The Organization and Integration of Cognition and Emotion in Development", Journal of Experimental Child Psychology, 67 (1997), pp. 303-316, p. 303 .

24 Cf. entre otros HAIDER, Hilde: "Emotionen als Steuerungselemente menschlichen Handelns" en Birgit ASCHMANN (ed.): Gefühl und Kalkül. Der Einfluss von Emotionen auf die Politik des 19. und 20. Jahrhunderts, Stuttgart, 2005, pp. 33-47, p. 40; BECHARA, A. / DAMASIO, H. / DAMASIO, A. R.: "Emotion, decision making and the orbitofrontal cortex", Cerebral Cortex, 10 (2000), pp. 295-307. DAMASIO, Hanna et al.: "The Return of Phineas Gage. Clues About the Brain from the Skull of a Famous Patient", Science, 264 (1994), pp. 1102-1105.

25 Cf. DESCARTES, René: Die Leidenschaften der Seele [1649], Hamburg, 1996.

26 Cf.. FRAZER, Michael L: The Enlightenment of Sympathy. Justice and the Moral Sentiment in the Eighteenth Century and Today, Oxford, 2010, p. 4.

27 Cf. REDDY, William: The Navigation of Feeling: A Framework for the History of Emotions, Cambridge, 2001, pp. 173-210.

28 STEARNS, Peter N. / STEARNS, Carol Z.: "Emotionology: Clarifying the History of Emotions and Emotional Standards", American Historical Review, 90 (1985), pp. 813-836, p. 813. 
ha habido fases en las que las emociones en general han jugado un papel más importante que en otras. La época de la sensibilidad, de la "sensibilité" en el siglo XVIII fue de gran importancia, le siguió una fase de sobriedad, de distanciamiento de las emociones, es decir, de la sustitución de las pasiones por sentimientos de honor, antes de que con la época del Romanticismo comenzara una nueva acentuación de los sentimientos, aunque la composición y la orientación de las emociones habían cambiado en gran medida: a las pasiones de la Ilustración, unidas a un fuerte impulso de acción política, les siguió una cierta disposición a la experiencia pasiva de los sentimientos. ${ }^{29}$ Es evidente que los "regímenes emocionales" dominantes se encontraban en una relación dialéctica similar a los sistemas políticos en la "era de las revoluciones". Por lo tanto, se trataría más bien de un cambio con grandes oscilaciones que de una línea continua, lo que se adecúa mejor a una imagen más duradera de la modernidad. ${ }^{30}$

\section{Intentos de control social de las emociones}

Es significativo que aquellos sentimientos que fueron apreciados según las reglas de la época no hayan sido considerados como irracionales, sino que eran más bien parte de una actitud considerada como adecuada y "correcta" por parte de los respectivos grupos sociales. Así, el amor y la esperanza en la Edad Media cristiana eran tan importantes como la fe en la razón. ${ }^{31}$ Conforme a esto, los Ilustrados escoceses estaban convencidos de que precisamente las emociones motivaban al ser humano a actuar de manera moralmente correcta y posibilitaban su existencia social. ${ }^{32}$ De esta manera, las emociones fueron racionalizadas sin problema: éstas eran consideradas parte de un comportamiento sensato, lógico y teleológico. ${ }^{33}$ Únicamente fueron tildados de "irracionales" aquellos sentimientos que se resistían a estas normas y que por eso amenazaban con poner en peligro la cohesión social, razón por la cual en las primeras teorías de las emociones, entre otras la de Descartes, era importante encauzar la carga sentimental y dominar los sentimientos que se resistían. ${ }^{34}$ Para evitar la temida "pérdida del control del cuerpo social" 35 a causa de emociones "erradas", se establecieron mecanismos de control colectivo de las emociones. Una forma de este control es en particular la patologización o criminalización de sensaciones individuales, es decir, de la desviación de una dosis supuestamente "adecuada" de sentimientos. ${ }^{36}$ Según Peter N. y Carol Z. Stearns, es la "emotionology", el conjunto de normas sociales, lo que no sólo determina lo decible, sino precisamente también "lo que se siente". Los Stearn no dejan claro hasta qué punto estas normas de la expresión de sen-

29 FRAZER, Michael L: Enlightenment; REDDY, William: Navigation, pp. 141-172, 211-256.

30 FLAM, Helena: Soziologie der Emotionen, pp. 98-101.

31 WASSMANN, Claudia: Die Macht der Emotionen. Wie Gefühle unser Denken und Handeln beeinflussen, 2. Auflage, Darmstadt, 2010, p. 20.

32 Según David Hume, entre otros; cf. PLAMPER, Jan: Geschichte und Gefühl, p. 32 y siguientes.

33 Cf. además NUSSBAUM, Martha: Upheaval of thought. The intelligence of emotions, Cambridge, 2001.

34 WASSMANN, Claudia: Macht der Emotionen, p. 25.

35 PLAMPER, Jan: Geschichte und Gefühl, p. 33.

36 Ibid., pp. 31-34. 
timientos pueden ejercer una influencia sobre las experiencias emocionales mismas. ${ }^{37} \mathrm{Fue}$ William Reddy quien intentó aclarar estas complejas interdependencias. Reddy indicó que el explicar las emociones (por ejemplo a través de la verbalización) no solo cumple una función autoexplorativa y descriptiva, sino que también repercute en el sentir de aquel que expresa la emoción, así como modifica los sentimientos de aquellos que son objeto de dicha expresión. Para comprender el potencial que tienen las emociones para transformar la realidad, Reddy - siguiendo la dimensión "performativa" de la teoría de los actos de habla - introdujo el término "emotive". ${ }^{38}$ De esta manera, se les atribuye a las emociones una "agency" propia que va más allá del simple contagio. Tanto más importante es para las sociedades, por su propio interés, controlar dichas fuerzas de cambio. Los esfuerzos emprendidos permiten suponer - de por sí con grandes inseguridades - lo difícil y arriesgado que pueden ser estos intentos de control.

En la temprana Edad Media se desarrolló como instrumento guía de las emociones la doctrina de los siete pecados capitales, doctrina que condenaba junto a la superbia, la avaritia, la luxuria, la ira, la gula y la invidia, también la acedia. ${ }^{39}$ Este último pecado parece ser especialmente poco definible y difícil de traducir. Se ha traducido como pereza, pero también como cobardía, ignorancia, indiferencia o "indolencia del corazón". ${ }^{40}$ Hyeronimus Bosch representó en Los Siete Pecados Capitales la acedia como un eclesiástico que le vuelve la espalda a una biblia cerrada. ${ }^{41}$ Se trata evidentemente de un estado de ánimo en el que se rompe la relación con Dios. En otros contextos, este estado de ánimo ha sido también llamado melancolía, el cual fue plasmado por Albrecht Dürer en una de sus tres Estampas Maestras en 1514, es decir, al comienzo de la Edad Moderna. ${ }^{42}$ Del misterioso grabado Melencolia I ha surgido una interpretación según la cual el cambio de la vieja a la nueva comprensión del mundo es el tema principal: símbolos de la fugacidad (reloj de arena) representan la despedida, a la vez que se ve acercarse un nuevo tiempo en el que se establece una relación entre el arte, el oficio manual y la ciencia: el arcoiris representa la bendición divina, el cual a su vez está en contraste con la acedia/melancolía. La melancolía, por una parte, es simbolizada por la postura corporal y la expresión facial de la figura; por otra, es nombrada explícitamente en la pancarta, la cual está sujeta por las alas de un dragón con alas de murciélago, criatura infernal: Melencolia I (lo que - como ha sido malinterpretado en reiteradas ocasiones - no representa un número ordinal, sino la forma imperativa de "ir" en latín, o sea: "Melancolía - ¡Vete! ¡Aléjate!") ${ }^{43}$. Durero tam-

\footnotetext{
37 STEARNS, Peter / STEARNS, Carol: „Emotionology“, p. 813.

38 REDDY, William: Navigation, p. 128; PLAMPER, Jan: "Wie schreibt man die Geschichte...?", p. 42 y siguientes.

39 Cf. el número temático "Die Sieben Todsünden in der Frühen Neuzeit", Frühneuzeit-Info, 21 (2010) Heft $1+2$.

40 SCHIRRMEISTER, Albert: "Kann denn Faulheit Sünde sein? Charles Auguste de La Fare, Virtuose des Müßiggangs“, Frühneuzeit-Info, 21 (2010), Heft 1+2, pp. 170-179.

41 POKORNY, Erwin: „Die sogenannte Tischplatte mit den Sieben Todsünden und den vier letzten Dingen“, Frühneuzeit-Info, 21 (2010), Heft 1+2, pp. 35-43.

42 Cf. entre otros THEUNISSEN, Michael: Vorentwürfe von Moderne. Antike Melancholie und die Acedia des Mittelalters, Berlin/New York, 1996, p. 26 y siguientes. Cf. también HERSANT, Yves: "Acedia und ihre Kinder", en: Jean CLAIR (ed.): Melancholie. Genie und Wahnsinn in der Kunst, Ostfildern-Ruit, 2005, pp. 54-59.

43 Agradezco al historiador del arte Ulrich Kuder por la aclaración, quien trabaja actualmente en una monografía sobre Dürer.
} 
bién describe los intentos por desterrar los sentimientos “turbios", oscuros (la melancolía era según la patología humoral de Galeno una sobreproducción de bilis negra),${ }^{44}$ como la desesperación, la cual era tan poco conciliable con el optimismo de una época de renovación como con los ideales cristianos y las orientaciones del capitalismo primitivo. ${ }^{45}$ A finales del siglo XVIII, en lugar del veredicto moral de origen religioso se introdujo la psicopatologización como medida para controlar las emociones. En lo sucesivo se leía en las enciclopedias de la época que "loco es quien no sabe dominar sus ansias, la ira, la venganza y la melancolía". ${ }^{46}$ La actitud de la melancolía y la criatura demoníaca con rasgos de murciélago fueron evocadas poco menos de trescientos años después de Durero por Francisco de Goya en un aguafuerte que llegaría a ser conocido como ícono de la Modernidad, ya que en ésta - a finales del siglo XVIII, justo después del terreur de la Revolución Francesa- dos interpretaciones de la Modernidad son proféticamente sugeridas. Se trata del Capricho 43: El sueño de la razón produce monstruos, el cual tematiza "aquel dilema entre razón y emoción" que llegaría a influenciar los dos siglos posteriores. ${ }^{47} \mathrm{La}$ ambivalencia intrínseca del cuadro yace en el doble sentido de la palabra "sueño". Según el sentido que se escoja, el significado toma una dirección divergente: primero es "solo" el sueño, el descanso momentáneo de la razón el que produce monstruos, de tal manera que muy de acuerdo con el pensamiento de la Ilustración, la razón deberá brillar incesantemente para que todos los monstruos puedan ser expulsados. Esto corresponde a la narrativa teórica de las emociones del control continuo de los afectos mencionada anteriormente. La segunda interpretación difiere de la primera en el sentido de que jes precisamente el "sueño", el anhelo de la razón el que produce monstruos! El "proyecto de la Modernidad" está según esto vinculado dialécticamente con el "otro de la razón". Este "otro de la razón" era, según Hartmut y Gernot Böhme,

visto desde la razón [...] lo irracional, lo irreal ontológicamente, lo indecoroso moralmente, lo ilógico lógicamente [...], en cuanto al contenido la naturaleza, el cuerpo humano, la fantasía, el deseo, los sentimientos - o mejor, todo esto, siempre que no se haya podido adueñar de la razón. ${ }^{48}$

Esta última consideración es determinante. Aquí no se trata de aquellos sentimientos que eran considerados como incentivos útiles para el bien común e individual, sino

44 Cf. entre otros DEMONT, Paul: „Der antike Melancholiebegriff: von der Krankheit zum Temperament“, en: Jean CLAIR, Melancholie, pp. 34-37.

45 SCHUSTER, Peter-Klaus: „Melencolia I. Dürer und seine Nachfolger“, en: Jean CLAIR, Melancholie, pp. 90-103.

46 HOFMANN, Werner: Goya. Vom Himmel durch die Welt zur Hölle, München, 2003, p. 141.

47 MENA MARQUÉS, Manuela B.: „Goya - Mensch seiner Zeit und Prophet der Moderne“, en PeterKlaus SCHUSTER / Wilfried SEIPEL (eds.): Goya. Prophet der Moderne. Ausstellungskatalog, Köln, 2005, pp. 11-22, p. 14. Sin embargo, no se puede probar que se trata de una cita intencionada, cf. SCHUSTER, Peter- Klaus: "Melencolia I", p. 101. Sobre una interpretación ver también HOFMANN, Werner: "Notizen zu Goyas Capricho 43" en idem: Bruchlinien. Aufsätze zur Kunst des 19. Jahrhunderts, München, 1973, p. 90 y siguientes; SCHUSTER, Peter-Klaus: „Unausdeutbar - Goyas Capricho 43 als Sinnbild der Moderne“ en Peter-Klaus SCHUSTER/ Wilfried SEIPEL, Goya, p. 33-41; JACOBS, Helmut C.: Der Schlaf der Vernunft. Goyas Capricho 43 in Bildkunst, Literatur und Musik, Basel, 2006.

48 BÖHME, Hartmut / BÖHME, Gernot: Das Andere der Vernunft. Zur Entwicklung von Rationalitätsstrukturen am Beispiel Kants, Frankfurt a. M. 1985, p. 13. 
precisamente de aquellos que se pensaba eran perjudiciales. Estos eran, según las enciclopedias de la época en la cultura española de finales del siglo XVIII, "monstruos" que - de acuerdo con la derivación etimológica de "monstrum" (emblema) o "mostrare" (mostrar) - remiten a algo artificial/poco natural, contrario a las reglas, fuera del orden más allá de la racionalidad, sin olvidar las "pasiones viciosas". ${ }^{49}$ Estos monstruos fueron en su mayoría ignorados en los discursos de la Ilustración. Sin embargo, los aguafuertes de Goya ilustran el hecho de que la represión de este "otro" no lleva a su desaparición. Una de las criaturas sombrías que es plasmada en repetidas ocasiones en sus pinturas y aguafuertes es el miedo, que por su parte remite a la melancolía; según Galeno, el melancólico era considerado como "aquel que ininterrumpidamente [...] se halla embargado por los miedos". 50

\section{El miedo en la era axial}

El miedo es considerado hoy como "el más basal de todos los sentimientos" o como el "alpha emotions in the hierarchy of human affects" $"$-, y es, de todas las emociones, la más estudiada. Esto se debe sobre todo a dos aspectos: por una parte, el gran interés terapéutico, justamente porque es una necesidad tratar el gran número de trastornos relacionados con el miedo en la sociedad actual, y por otra, la sencilla reproducibilidad técnica de este sentimiento- siempre y cuando nos refiramos exactamente a aquellas reacciones de miedo físicas y universales relativamente rápidas a las que se está haciendo referencia, las cuales no tienen aquí ningún papel. Más bien nos referimos a un miedo relacionado con percepciones e interpretaciones del mundo que apuntan a disposiciones colectivas y con ello a un profundo cambio en la sociedad. Con su estudio sobre "La historia de los miedos colectivos en Europa entre los siglos XIV y XVIII" mencionado anteriormente, ${ }^{52}$ Jean Delumeau explica el cambio que se ha dado en el paso de la Edad Media a la Edad Moderna. Observa que a comienzos de la Edad Moderna se incrementaron los sentimientos de miedo, los cuales alcanzaron su punto máximo en el siglo XVII antes de que llegara una "relajación", una "curación de la cultura occidental" en el siglo XVIII. El aumento del miedo se puede ver en la relación directa con la Guerra de los Treinta Años, como lo confirma Andreas Bähr. ${ }^{53}$ Pero incluso en el discurso del miedo del siglo XVII, Bähr to-

49 Cf. Esteban de TERREROS Y PANDO: Diccionario castellano con las voces de ciencias y artes y sus correspondientes en las tres lenguas francesa, latina e italiana, Madrid 1787, tomo 2, pp. 612-613. Aquí se da una asombrosa coincidencia con la definición de Heinz-Gerhard Friese, quien dedica a los „monstruos“" un largo capítulo en su historia de la cultura sobre "La estética de la noche" publicada en 2011. Cf. FRIESE, Heinz-Gerhard: Die Ästhetik der Nacht. Eine Kulturgeschichte, Hamburg, 2011. Aquí sobre los capítulos "Monster" (pp. 443-579) y "Monster im Spiegel der Nacht" (pp. 580-719).

50 GALENUS, Claudius: De locis affectis, Bd. VIII p. 189, citado en DEMONT: Der antike Melancholiebegriff, p. 36.

51 KAGEN, Jerome: What is Emotion? History, Measures, and Meanings, New Haven, 2007, p. 14, citado por Jan PLAMPER, Jan / LAZIER, Benjamin: "Introduction: The Phobic Regimes of Modernity", Representations, 110 (2010), 1, pp. 58-65, p. 59.

52 DELUMEAU, Jean: Angst; Ya Huizinga había hecho de la Baja Edad Media un tiempo del miedo, porque se trataba de una época de crisis. HUIZINGA, Johann: Herbst, p. 24.

53 BÄHR, Andreas: Furcht und Furchtlosigkeit. Göttliche Gewalt und Selbstkonstitution im 17. Jahrhundert, Göttingen, 2013. 
davía ve la influencia de mecanismos religiosos, que acabaron prescribiendo y posibilitaron la superación del mismo. ${ }^{54}$ De esta manera, estas herramientas religiosas de superación relativizan la idea de una Premodernidad fundamentalmente permeada de miedo. Mejor aun, es precisamente la pérdida de este medio de mitigación y superación como resultado del proceso moderno de secularización el que le otorga una nueva propiedad. Goya se encontraba aquí en el punto de encuentro entre el discurso optimista de la Ilustración, el cual concebía el miedo como un estado emocional erróneo que se debía superar con ayuda de la razón, y el discurso del miedo moderno originado por una vaga certeza acerca del futuro. Sus obras son testigo de una nueva representación de la "emotionology" referente al miedo y que surgió a comienzos del siglo XIX en el contexto de un cambio de época radical. Este cambio puede ser ejemplarizado a través de algunos de sus aguafuertes. ${ }^{55}$ En el capricho Que viene el Coco se ven dos niños que claramente quieren huir del Coco y que con un gesto de terror se arrojan a los brazos de su madre. En el siglo XIX se había impuesto la idea de que la expresión facial proporcionaba un conocimiento inmediato de los sentimientos y por eso se le daba mucha importancia a la representación de los rasgos faciales. A partir de ahí se desarrolló un canon que prescribía cómo el artista debía representar cada emoción a través de gesticulación y mímica. ${ }^{56} \mathrm{Si}$ se observa con cuidado el Capricho de Goya, llama la atención que la expresión facial de la madre es muy diferente de la de sus hijos, en cuanto ella refleja más complacencia que miedo. El comentario aún conservado de Goya lo aclara: a las madres les gustaba hablar del Coco cuando se querían encontrar con sus amantes. Rresulta por eso es evidente que es precisamente la madre la que no tranquiliza a sus hijos, sino la que alimenta sus miedos porque esto le es útil. Con esta crítica a la instrumentalización del miedo, Goya seguro que tenía en mente no solo la esfera de la educación en el interior de la familia, sino sobre todo las instituciones políticas y religiosas que utilizaban el miedo como medio disciplinario. Conforme a esto, el miedo no aparece en el catálogo de los siete pecados capitales, pues éste era considerado una emoción útil. "Fear", como lo exageró un poco Joanna Bourke, "was the rock upon which Christ built his church". ${ }^{57}$ Esto puede haber sido válido especialmente para la iglesia en España, en la que la Inquisición había establecido durante varios siglos una "pedagogía del miedo". ${ }^{58}$ En el siglo XVIII, el miedo fue a parar al banquillo de los acusados. El aguafuerte de Goya es sólo un ejemplo de que con sus obras tomó parte en el discurso ilustrado que quería desterrar el miedo desenmascarando las representaciones que lo utilizaban para engañar, o lo que es más, como instrumento de dominio. Aquí el

54 BÄHR, Andreas: „Unaussprechliche Furcht“ und Theodizee. Geschichtsbewusstsein im Dreißigjährigen Krieg“, WerkstattGeschichte, 49 (2008), pp 9-31.

55 ASCHMANN, Birgit: Der Traum der Vernunft und seine Monster. Goyas Perspektiven auf das 19. Jahrhundert, Berlin, 2013.

56 SCHMIDT, Anne: "Gefühle zeigen, Gefühle deuten" en Ute FREVERT et al.: Gefühlswissens. Eine lexikalische Spurensuche in der Moderne, Frankfurt a. M. 2011, pp. 65-91, p. 71. La convicción de poder deducir emociones "verdaderas" a partir de las expresión faciales fue desarrollada en el siglo XX por Paul Ekman, quien a su vez se basó en Darwin. Sobre la crítica a su método ver LEYS, Ruth: "How Did Fear Become a Scientific Object and What Kind of Object Is it?", Representations, 110 (2010), 1, pp. 66-104.

57 BOURKE, Joanna: "Fear and Anxiety: Writing about Emotion in Modern History", History Workshop Journal, 55 (2003), pp. 111-133, p. 118.

58 Según Bartolomé Benassar, citado en: LA PARRA, Emilio y CASADO, María Ángeles: La Inquisición en España. Agonía y abolición, Madrid, 2013, p. 28. 
miedo es tematizado - muy de acuerdo con Delumeau - como algo que solo puede ser superado si la razón pasa a dominar (aquí es el sueño, el descanso de la razón el que produce monstruos...). Sin embargo, en sus obras tardías, Goya fue representando cada vez más un miedo que ya no era fácil de manejar. Ya no eran la Inquisición y la brujería las que le inquietaban. En una carta a un amigo Goya escribió: "Yo confieso que me aturdí al principio, pero aora? [sic] Ya, ya, ya ni temo a Brujas, duendes, fantasmas, balentones [sic] Gigantes, follones, malandrines etc. ni ninguna clase de cuerpos temo sino a los humanos". ${ }^{59} \mathrm{Al}$ ser humano - y ya no a un poder divino trascendental que le atribuye un sentido superior a todo lo terrenal - se le fue haciendo cada vez más responsable de su evolución interna. Pero según el credo de la época burguesa, el ser humano era sobre todo libre. Libre de hacer el bien o el mal. Esta libertad era para Kierkegaard la condición previa para tener miedo ${ }^{60}$ Qué tan justificado era este miedo se le mostró a la sociedad española en la guerra de la independencia contra Napoleón, y su brutalidad fue plasmada por Goya en los aguafuertes Desastres de la Guerra. Éstos se caracterizan tanto por su impresión realista como por una densidad iconográfica tal, que se convirtieron en símbolo intemporal de condena a la guerra. En una exposición del Instituto Cervantes de Berlín en 2012, estos aguafuertes fueron colgados justo al lado de fotografías que tenían como tema las guerras de los siglos XIX y XX. Allí, Goya fue calificado como "cronista de todas las guerras", ${ }^{61}$ pues parece ser que la brutalidad de los autores de la guerra, el sufrimiento de las víctimas y las preguntas existenciales traídas a la memoria son temas que se volvieron recurrentes no solo debido a las grandes guerras del siglo XX. Justamente por eso es tentador considerar a Goya como el testigo de cargo de unos momentos de transformación de importancia única que tienen que ver con el miedo. La desesperación, el miedo y el pánico se vuelven tema frecuente en sus cuadros. Junto con el miedo a los efectos inmediatos de la violencia, Goya también representa el potencial contagioso del pánico en masa. Con frecuencia, en sus cuadros, el agresor está ausente, Goya le niega al espectador la mirada identificadora de las causas de ese miedo, lo que puede ser interpretado como muestra de que las explicaciones comunes, tradicionales (jreligiosas!) ya no parecen satisfacer. La certeza de sentirse a salvo en manos de Dios deja paso a causa de la experiencia de la guerra a un miedo general al futuro. Así, el aguafuerte "tristes presentimientos de lo que va a acontecer" (Desastres de la Guerra No. 1) no solo simboliza el miedo contemporáneo a la guerra inminente - un miedo que hasta bien avanzadas las guerras mundiales fue percibido como lo "realmente grave". El aguafuerte también simboliza el cambio paradigmático de un temor relacionado con el objeto hacia un miedo general, incierto hacia el futuro. Éste también va acompañado por el miedo a la pérdida de sentido. En las representaciones de la guerra de Goya, el hecho de que los hombres se maten de manera brutal "con razón y sin ella" 62 debe inquietar profundamente al espectador, quien no puede relacionar de manera "racional" la banalidad del motivo con la brutalidad de lo

59 Ver carta n 123 [sin fechar 1792] en: Francisco de Goya: Cartas a Martín Zapater, ed. por Mercedes AGUEDA / Xavier DE SALAS, Madrid, 1982, p. 210.

60 KIERKEGAARD, Sören: Der Begriff Angst, ed. por Hans ROCHOL, Hamburg, 1984, p. 79.

61 Goya. Cronista de todas las guerras: Los Desastres y la fotografia de guerra, ed. por el Instituto Cervantes de Berlín y la Calcografía Nacional. Real Academia de Bellas Artes de San Fernando, Madrid/ Berlin, 2012. Exposición del Instituto Cervantes de Berlín 13.2.-30.03.2012.

62 El aguafuerte $n^{\circ} 2$ de la serie "Desastres de la guerra" lleva el subtítulo "con razón y sin ella“. 
ocurrido. Así, los aguafuertes de Goya permite echar una mirada en lo más profundo del ser humano, quien también sin razón está dispuesto a hacer el mal y a deleitarse en él. A través de medios estéticos Goya disecciona un sadismo que no tiene nada que ver con vencer al enemigo. En numerosos cuadros éste no solo es asesinado sino despedazado meticulosamente. El sinsentido del matar, el cual no es mitigado ni por la promesa de una resurrección inmanente al mundo ni de una resurrección trascendental, culmina para Goya en un nihilismo temprano que evoca a Schopenhauer, quien termina su obra principal con la palabra "nada". ${ }^{63}$ En el Desastre n ${ }^{\circ} 69$, un cadáver en descomposición sujeta en la mano una hoja de papel con la palabra "Nada" desde la tumba. Ese miedo a la muerte sin sentido, el miedo a la desgracia inminente, el miedo al futuro y el miedo al propio abismo fueron preservados en los siglos siguientes y se popularizaron especialmente en tiempos de guerra y de crisis. Este miedo nunca ha sido considerado como funcional y conveniente, por lo que la propaganda política debía estimular el optimismo de la sociedad y la psicología militar de los soldados. ${ }^{64}$ Precisamente en el mundo de hoy, en el que en territorios en guerra cada vez es más difícil distinguir entre "el bien" y "el mal", y donde en el mundo occidental el mal - absolutamente sin sentido - puede acechar en aeropuertos o en estaciones de metro, parece estar justificado hablar de una era del miedo. De esta manera, el miedo no es "the most archaic" sino también "the most modern of emotions". ${ }^{65}$

\section{Consideraciones finales: emociones y Modernidad}

La idea de una Modernidad con un avanzado control de los afectos es solo hasta cierto punto conciliable con todo lo expuesto. Pero incluso si estuviéramos de acuerdo en dar por terminada la Modernidad en 1972 -con el inicio de la crisis del petróleo-, aún queda por comprobar que también la sociedad de la Guerra Fría conocía el miedo y una política bajo el miedo. ${ }^{66}$

En general se puede decir que es evidente que en la Modernidad hubo una evolución: un miedo entendido originariamente como premoderno, religioso y positivo se convirtió en un miedo que amenazaba a la sociedad y al individuo; un miedo que podía fusionarse con acedia-melancolía hacia la desesperación, y el cual ya no podía ser eliminado con la promesa religiosa de dar un sentido al mundo. Queda entonces reducida a tan solo una evolución entre muchas, tal y como la interpretación religiosa del mundo no llegó a desa-

63 SCHOPENHAUER, Arthur: „Die Welt als Wille und Vorstellung“, en: Werke in zehn Bänden, 2. Vol., Zürich, 1977, p. 509.

64 Cf. entre otros MICHL, Susanne / PLAMPER, Jan: „Soldatische Angst im Ersten Weltkrieg. Die Karriere eines Gefühls in der Kriegspsychiatrie Deutschlands, Frankreichs und Russlands", Geschichte und Gesellschaft 35, 2 (2009), pp. 209-248.

65 PLAMPER, Jan / LAZIER, Benjamin "Introduction", p. 59.

66 Cf. entre otros NEHRING, Holger: "Angst, Gewalterfahrungen und das Ende des Pazifismus. Die britischen und westdeutschen Proteste gegen Atomwaffen, 1957-1964“, en Bernd GREINER (ed.): Angst im Kalten Krieg, Hamburg, 2009, pp. 436-464; BIESS, Frank: „Die Sensibilisierung des Subjekts: Angst und "Neue Subjektivität" in den 1970er Jahren“, WerkstattGeschichte, 49 (2008), pp. 51-71. 
parecer. En las "multiple Modernities", ${ }^{67}$ que también habían surgido antes de la Posmodernidad, se puede encontrar una variedad de emociones, de comunidades emocionales con sus respectivos estilos. ${ }^{6}$ Hasta qué punto la manera en que sentimos y expresamos sentimientos está influenciada por una predisposición genética, por la estructura cerebral o por la socialización, es algo que probablemente no pueda llegar a ser nunca aclarado del todo. En el campo de la historia de las emociones sigue habiendo más preguntas que respuestas. Desde esta perspectiva, la pregunta de hasta qué punto la Modernidad fue una Era Axial - en el sentido de Karl Jaspers- no va a ser fácil de responder. En todo caso no se trató de una época de racionalización si la contemplamos en términos de una desaparición de las emociones.

Con referencia al concepto de Modernidad, y como ha esbozado Christoph Dipper, que por una parte ha resaltado los procesos básicos y por otra, los modelos de orden que constituyen una guía de orientación, basada en la percepción de una época determinada, se debe decir lo siguiente: 1. Las emociones siempre están presentes en toda decisión, y en este sentido también en todo proceso básico. Como proceso básico de la Modernidad específicamente emocional debe mencionarse el reflexionar sobre las emociones en beneficio de un control de los afectos, más que un control de los mismos como tal (esto último ya había ocurrido en la Edad Media). Pero esto implica en última instancia que con respecto a la relevancia de las emociones para un concepto nuevo de Modernidad, se ha ganado poco conocimiento. Lo que es más importante aquí es el significado fundamental de las emociones para la evolución de lo que Dipper llama "modelo de orden": se trata de grandes velas que la sociedad abre hasta el punto de que los vientos dirigen la barca en una u otra dirección. La función de dirección la asumen las emociones. ${ }^{69}$ Sin el miedo a la revolución, la hegemonía del "orden" en la época posrevolucionaria es inimaginable; sin optimismo no puede haber progreso. Para poder dirigir la barca "correctamente" se necesita de instrucción, hay que inculcar normas. Aquí también se puede mencionar a Reddy y su así llamado "régimen emocional", el cual ayuda en la navegación. En la consolidación de este canon de normas se trabaja socialmente con estrategias de marginación/exclusión, que estigmatizan comportamientos emocionales no deseados como regresivos ontogenética y patológicamente o como inhumanos: las reacciones emocionales son por eso calificadas de "infantiles", "enfermizas" o "animales". ${ }^{70}$ De esta manera, es un componente del proceso de maduración del hombre occidental el hecho de que los niños aprenden a posponer emociones impulsivas de egoísmo y destrucción a favor de intereses comunes y a largo plazo. El problema surge cuando estos mecanismos ya no funcionan o regímenes emocionales de diversas culturas (o, según Barbara Rosenwein, de comunidades emocio-

67 EISENSTADT, Shmuel N. (Hg.): Multiple Modernities, New Brunswick, 2002; idem.: Die Vielfalt der Moderne, Weilerswist, 2000.

68 Cf. entre otros GAMMERL, Benno: "Introduction: Emotional Styles - Concepts and Challenges", Rethinking History, 16 (2012), pp. 161-175.

69 ILOUZ, Eva: Gefühle in Zeiten des Kapitalismus. Adorno-Vorlesungen 2004, Frankfurt a. M. 2006, p. 10 .

70 Cf. entre otros ELIAS, Norbert: Prozeß, p. 370; HUIZINGA, Johann: Herbst, pp. 25, 29. LUHMANN, Niklas: Liebe. Eine Übung, Frankfurt a. M. 2008, p. 18. Kant consideraba como „infantiles“ a aquellos que se dejaban llevar por los afectos. Cf. KANT, Immanuel: "Anthropologie in pragmatischer Absicht", en: Kants gesammelte Schriften, ed. por Königlich Preußischen Akademie der Wissenschaften Bd. VII, Berlin, 1968, p. $235 \mathrm{y}$ siguientes. 
nales diversas) chocan unos con otros. La popularidad disminuida de estos modelos sociales podría ser decisiva para el crecimiento de la disposición al conflicto, y esto impulsa la desaparición de las normas emocionales. Si la "cultura de la empatía" puede actuar en su contra, es incierto. Asimismo, parece ser poco claro si la Modernidad realmente, como afirma Ute Frevert, puede ser caracterizada como la época del auge de esta emoción, especialmente porque la empatía, como lo explica Hennig Ritter, debe ser pensada dialécticamente con su opuesto: la crueldad. ${ }^{71}$ Sin embargo, estas contradicciones estuvieron siempre presentes en toda la Modernidad. Lo ambivalente, lo destructivo, lo oscuro en el ser humano que, en los discursos de la Modernidad se trataba como algo "patológico" y "animal", probablemente nunca existieron, especialmente si se tiene en cuenta que en situaciones de guerra la empatía general fue oficialmente abandonada. A qué excesos condujo esto no lo demostraron por primera vez las guerras del siglo XX: Goya ya lo había hecho antes. La inclusión de las emociones en los discursos sobre la Modernidad aclara la perspectiva de que no solo estamos teniendo que ver con "modernities" múltiples, sino también contradictorias.

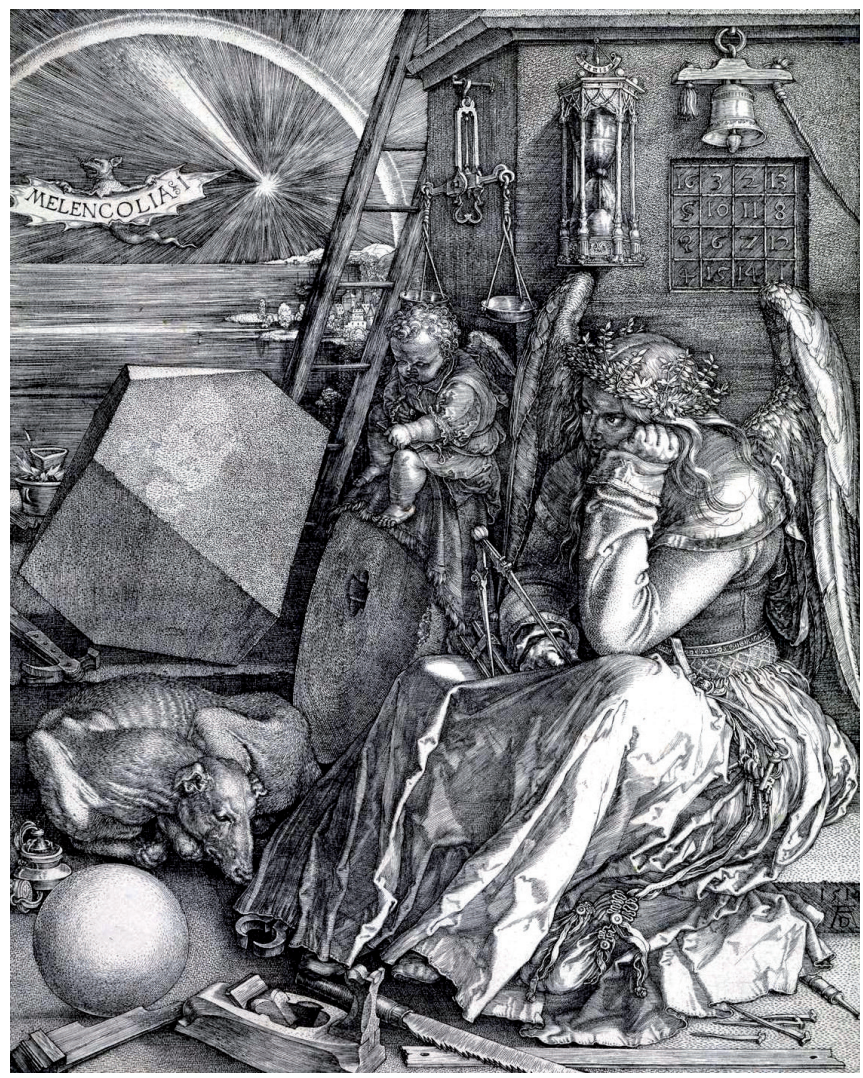

Fig. 1. Melancolia de Durero.

71 FREVERT, Ute: "Mitleid und Empathie“, en idem: Vergängliche Gefühle, Göttingen, 2013, pp. 44-74; RITTER, Henning: Die Schreie der Verwundete. Versuch über die Grausamkeit, München, 2013. 


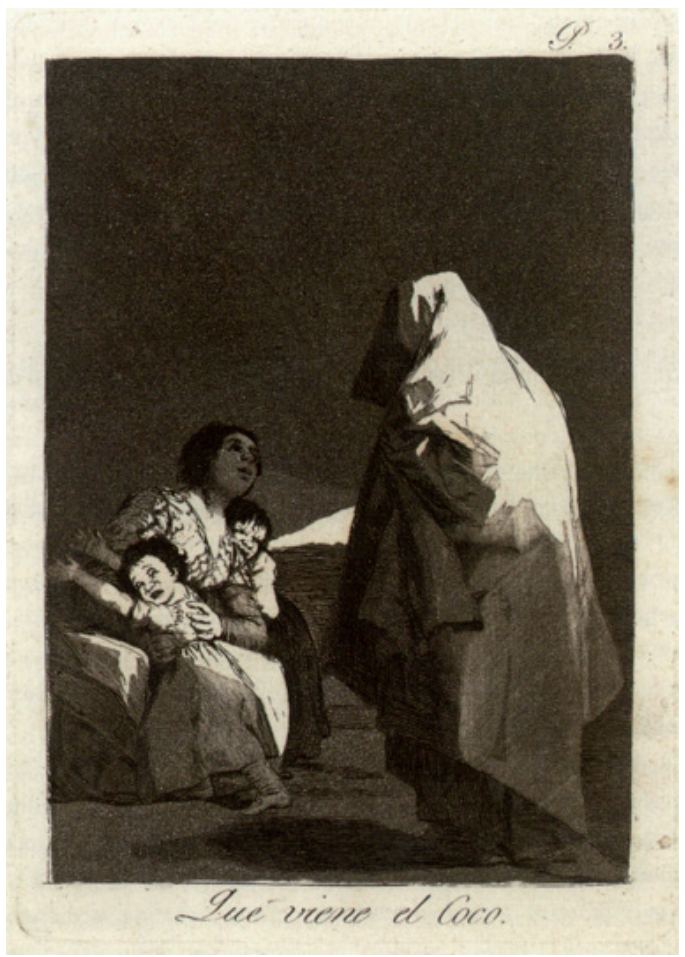

Fig. 2. Que viene el coco, Goya

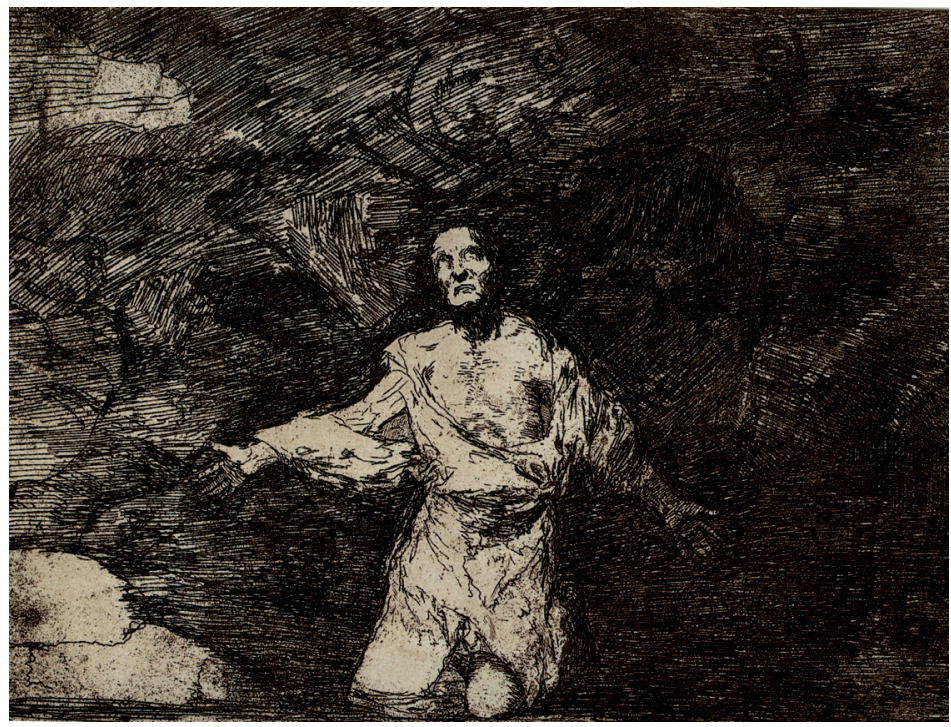

Fig. 3. Los desastres de la guerra, Goya. 